Louisiana State University

LSU Digital Commons

7-1-2009

\title{
Decomposition in tropical forests: A pan-tropical study of the effects of litter type, litter placement and mesofaunal exclusion across a precipitation gradient
}

\author{
Jennifer S. Powers \\ University of Minnesota System \\ Rebecca A. Montgomery \\ University of Minnesota System \\ E. Carol Adair \\ University of Minnesota System \\ Francis Q. Brearley \\ Manchester Metropolitan University \\ Saara J. Dewalt \\ Clemson University
}

See next page for additional authors

Follow this and additional works at: https://digitalcommons.Isu.edu/biosci_pubs

\section{Recommended Citation}

Powers, J., Montgomery, R., Adair, E., Brearley, F., Dewalt, S., Castanho, C., Chave, J., Deinert, E., Ganzhorn, J., Gilbert, M., González-Iturbe, J., Bunyavejchewin, S., Grau, H., Harms, K., Hiremath, A., Iriarte-Vivar, S., Manzane, E., De Oliveira, A., Poorter, L., Ramanamanjato, J., Salk, C., Varela, A., Weiblen, G., \& Lerdau, M. (2009). Decomposition in tropical forests: A pan-tropical study of the effects of litter type, litter placement and mesofaunal exclusion across a precipitation gradient. Journal of Ecology, 97 (4), 801-811.

https://doi.org/10.1111/j.1365-2745.2009.01515.x

This Article is brought to you for free and open access by the Department of Biological Sciences at LSU Digital Commons. It has been accepted for inclusion in Faculty Publications by an authorized administrator of LSU Digital Commons. For more information, please contact ir@lsu.edu. 


\section{Authors}

Jennifer S. Powers, Rebecca A. Montgomery, E. Carol Adair, Francis Q. Brearley, Saara J. Dewalt, Camila T. Castanho, Jerome Chave, Erika Deinert, Jörg U. Ganzhorn, Matthew E. Gilbert, José Antonio GonzálezIturbe, Sarayudh Bunyavejchewin, H. Ricardo Grau, Kyle E. Harms, Ankila Hiremath, Silvia Iriarte-Vivar, Eric Manzane, Alexandre A. De Oliveira, Lourens Poorter, Jean Baptiste Ramanamanjato, Carl Salk, Amanda Varela, George D. Weiblen, and Manuel T. Lerdau 


\title{
Decomposition in tropical forests: a pan-tropical study of the effects of litter type, litter placement and mesofaunal exclusion across a precipitation gradient
}

\author{
Jennifer S. Powers ${ }^{1 *}$, Rebecca A. Montgomery ${ }^{2}$, E. Carol Adair ${ }^{3}$, Francis Q. Brearley ${ }^{4}$, \\ Saara J. DeWalt ${ }^{5}$, Camila T. Castanho ${ }^{6}$, Jerome Chave $^{7}$, Erika Deinert ${ }^{8}$, Jörg U. Ganzhorn ${ }^{9}$, \\ Matthew E. Gilbert ${ }^{10}$, José Antonio González-Iturbe ${ }^{11}$, Sarayudh Bunyavejchewin ${ }^{12}$, \\ H. Ricardo Grau ${ }^{13}$, Kyle E. Harms ${ }^{14}$, Ankila Hiremath ${ }^{15}$, Silvia Iriarte-Vivar ${ }^{16}$ †, Eric Manzane ${ }^{17}$, \\ Alexandre A. de Oliveira ${ }^{6}$, Lourens Poorter ${ }^{18}$, Jean-Baptiste Ramanamanjato ${ }^{19}$, Carl Salk ${ }^{20}$, \\ Amanda Varela ${ }^{21}$, George D. Weiblen ${ }^{22}$ and Manuel T. Lerdau ${ }^{23}$ \\ ${ }^{1}$ Department of Ecology, Evolution and Behavior, and Plant Biology, University of Minnesota, MN 55108, USA; ${ }^{2}$ Forest \\ Resources, University of Minnesota, MN 55108, USA; ${ }^{3}$ Ecology, Evolution and Behavior and Soil, Water and Climate, \\ University of Minnesota, MN 55108, USA; ${ }^{4}$ Department of Environmental and Geographical Sciences, Manchester \\ Metropolitan University, Chester Street, Manchester M1 5GD, UK; ${ }^{5}$ Department of Biological Sciences, Clemson \\ University, 132 Long Hall, Clemson, SC 29634, USA; ${ }^{6}$ Instituto de Biociências, Universidade de São Paulo, São Paulo, \\ Brazil; ' Laboratoire Evolution et Diversité Biologique, UMR5174 CNRS/UPS, Bâtiment 4R3, 118 route de Narbonne, \\ 31062 Toulouse, France; ${ }^{8}$ Organization for Tropical Studies, San Jose, Costa Rica; ${ }^{9}$ Department of Animal Ecology and \\ Conservation, Hamburg University, Martin-Luther-King Platz 3, 20146 Hamburg, Germany; ${ }^{10}$ Department of Organismic \\ and Evolutionary Biology, Harvard University, Cambridge, MA 02138, USA; ${ }^{11}$ Biocenosis A. C., Calle 4 No. 356 x 11 y 15. \\ Col. Las Águilas CP 97134, Mérida, Yucatán, Mexico; ${ }^{12}$ National Parks, Wildlife and Plant Conservation Department, \\ Research Office, Chatuchak, Bangkok 10900, Thailand; ${ }^{13}$ Conicet-Liey, Facultad de Ciencias Naturales, Universidad \\ Nacional de Tucumán, San Miguel de Tucumán, Argentina; ${ }^{14}$ Department of Biological Sciences, Louisiana State \\ University, 202 Life Sciences Building, Baton Rouge, LA 70803, USA and Smithsonian Tropical Research Institute, Balboa, \\ Ancon, Republic of Panama; ${ }^{15}$ Ashoka Trust for Research in Ecology and the Environment (ATREE), K-1 Commercial \\ Complex, Birbal Road, Jangpura Extensión, New Delhi 110014, India; ${ }^{16}$ Unidad de Recursos Naturales, Centro de \\ Investigación Científica de Yucatán A.C., Calle 43 No. 130, Chuburna de Hidalgo 97200, Mérida, Yucatán, México; \\ ${ }^{17}$ Department of Biology, University of Miami, Coral Gables, FL 33146, USA; ${ }^{18}$ Forest Ecology and Forest Management \\ Group and Resource Ecology Group, Centre for Ecosystem Studies, Wageningen University, P.O. Box 47, 6700 AA \\ Wageningen, The Netherlands and Instituto Boliviano de Investigación Forestal, Casilla 6204, Santa Cruz, Bolivia; ${ }^{19}$ QIT \\ Madagascar Minerals, BP 225, Tolagnaro 614, Madagascar; ${ }^{20}$ Department of Biology, Duke University, Durham, NC \\ 27708, USA; ${ }^{21}$ Laboratorio de Ecología de Suelos y Hongos Tropicales, Unidad de Ecología y Sistemática, Departamento \\ de Biología, Facultad de Ciencias, Pontificia Universidad Javeriana, Bogotá, Colombia; ${ }^{22}$ Plant Biology and the Bell \\ Museum of Natural History, University of Minnesota, MN 55108, USA; and ${ }^{23}$ Environmental Sciences and Biology \\ Departments, University of Virginia, 291 McCormick Rd, Charlottesville, VA 22904, USA
}

\begin{abstract}
Summary
1. Litter decomposition recycles nutrients and causes large fluxes of carbon dioxide into the atmosphere. It is typically assumed that climate, litter quality and decomposer communities determine litter decay rates, yet few comparative studies have examined their relative contributions in tropical forests.

2. We used a short-term litterbag experiment to quantify the effects of litter quality, placement and mesofaunal exclusion on decomposition in 23 tropical forests in 14 countries. Annual precipitation varied among sites $(760-5797 \mathrm{~mm}$ ). At each site, two standard substrates (Raphia farinifera and Laurus nobilis) were decomposed in fine- and coarse-mesh litterbags both above and below ground for approximately 1 year.
\end{abstract}

\footnotetext{
*Correspondence author. E-mail: powers@umn.edu

$\dagger$ Present address: Facultad de Ciencias, Departamento de Ecología y Recursos Naturales, Universidad Nacional Autónoma de México, Circuito Exterior, Ciudad Universitaria, C.P. 04510, México, D.F.
} 
3. Decomposition was rapid, with $>95 \%$ mass loss within a year at most sites. Litter quality, placement and mesofaunal exclusion all independently affected decomposition, but the magnitude depended upon site. Both the average decomposition rate at each site and the ratio of above- to below-ground decay increased linearly with annual precipitation, explaining $60-65 \%$ of among-site variation. Excluding mesofauna had the largest impact on decomposition, reducing decomposition rates by half on average, but the magnitude of decrease was largely independent of climate. This suggests that the decomposer community might play an important role in explaining patterns of decomposition among sites. Which litter type decomposed fastest varied by site, but was not related to climate. 4. Synthesis. A key goal of ecology is to identify general patterns across ecological communities, as well as relevant site-specific details to understand local dynamics. Our pan-tropical study shows that certain aspects of decomposition, including average decomposition rates and the ratio of above- to below-ground decomposition are highly correlated with a simple climatic index: mean annual precipitation. However, we found no relationship between precipitation and effects of mesofaunal exclusion or litter type, suggesting that site-specific details may also be required to understand how these factors affect decomposition at local scales.

Key-words: above ground, below ground, climate decomposition index, decomposition, decomposer fauna, litter type, precipitation, tropical forests

\section{Introduction}

Decomposition of dead plant material is an important process by which carbon fixed during photosynthesis is returned to the atmosphere (Schlesinger 1977; Singh \& Gupta 1977), and is critical for nutrient cycling (Swift et al. 1979, Sayer 2006). As a primarily biotic process, decomposition and concomitant $\mathrm{CO}_{2}$ release and nutrient mineralization depend upon a number of drivers that directly and indirectly affect decomposer activity. Empirical studies, conducted largely in the temperate zone, have identified three key drivers of decomposition, in order of decreasing importance: climate, litter quality (e.g. chemical composition) and the decomposer community (e.g. bacteria, fungi and soil fauna) (Meentemeyer 1978, 1984; Coûteaux et al. 1995). Despite the established importance of the decomposer community (Seastedt 1984; Bradford et al. 2002a), it is typically assumed that decomposition can be modelled using climate and litter chemistry data alone, with either no or very minimal information on the decomposer community (e.g. microbial biomass data; but see Moorhead \& Sinsabaugh 2006; Wall et al. 2008). Models also typically assume that above- and below-ground decomposition are controlled by the same factors (Moorhead et al. 1999). Several lines of evidence suggest that these assumptions may not always hold, especially in tropical ecosystems.

Evidence from tropical ecosystems suggests that the importance of biotic factors may vary with climate and litter position (above- or below ground). Lavelle et al. (1993) proposed that the hierarchy of factors regulating decomposition differs between humid tropical ecosystems and drier forests, for example, biotic factors may be more important than abiotic factors in humid ecosystems. For example, González and Seastedt (2001) found that excluding fauna had little effect on decomposition rates in a tropical dry forest and significant effects in a tropical wet forest, suggesting that arthropod importance in tropical ecosystems may vary as a function of rainfall. A recent global-scale study also confirmed the differential stimulatory effect of soil fauna on decomposition in wet climates compared to cold or dry environments (Wall et al. 2008). Furthermore, taxonomic richness contributed more to this effect than abundance (Wall et al. 2008).

Other studies have shown major differences in decomposition above- and below ground, between wet and dry tropical forests. Decomposition data for five tropical forests in Central America and Puerto Rico presented in Gholz et al. (2000) indicated that leaf litter decomposed faster than roots in wet forests, while roots decomposed faster than leaves in dry forests. Additional evidence confirms that different factors may control decomposition dynamics above- and below ground. In a review of root decomposition, Silver and Miya (2001) found that one aspect of litter quality, calcium concentration, was a better predictor of fine root decay rates than climate. Collectively, these results suggest that tropical forests differ in the factors that influence decomposition rates of above- and below-ground litter and the degree to which decomposition is controlled by soil fauna. However, because global meta-analyses (Cornwell et al. 2008) or global network experiments (Gholz et al.2000) typically only include a limited number of tropical sites, the extent to which these patterns can be generalized across tropical forests is not known.

We used a short-term decomposition study in 23 tropical forests to investigate the influences of climate, litter type and soil fauna on litter decomposition. Most lowland tropical forests experience continually warm climates but vary greatly in the amount and seasonal distribution of precipitation (Dewar \& Wallis 1999). Our sites comprise a large gradient in mean annual precipitation (MAP) and dry season length (DSL). Rather than imposing arbitrary categories on these climatic regimes like 'dry' or 'wet', we used the continuous variation in climate as a predictor in our analyses. To sample 
a wide range of forests, we assembled a network of collaborators, each implementing standardized protocols with two common litter types, which were decomposed above- and below ground in fine- and coarse-mesh litterbags to exclude or include mesofauna. We predicted that the degree to which decomposition is controlled by soil fauna and litter chemistry would vary with precipitation regime. Specifically, we expected that the reduction in decomposition due to excluding soil mesofauna would increase with increasing precipitation, and that the difference in decomposition between low- and high-quality substrates would decrease with increasing precipitation. Finally, we predicted that decomposition would be faster below- than above-ground in drier forests, while the converse would be true in wetter forests.

\section{Methods}

\section{STUDY SITES}

We conducted our experiment in 23 tropical forests in 14 countries (Table S1 in Supporting Information, Fig. 1). Vegetation at all of the sites is unmanaged and species composition, soil type and nutrient availability vary widely among sites. The sites encompass a modest range of mean annual temperature (MAT: $11-27^{\circ} \mathrm{C}$ ), and a large range of MAP (760-5797 mm) and DSL (the number of months with precipitation $<100 \mathrm{~mm}$; from 0 to 9 months). Many of our field sites are remote, so even simple climatic data are difficult to obtain (Clark 2007). Thus, one of our sites (ULU) lacks temperature data.

Climate data (Table S1) come from published or unpublished site measurements. In addition to site-derived climate data, we collated monthly temperature and precipitation estimates from a 1-km spatial resolution mapped database, 'WorldClim' (Hijmans et al. 2005). We used these data to calculate a Climate Decomposition Index (CDI) for each site. A CDI describes the effect of monthly variation in temperature and water on decomposition (Parton et al. 2007). The water function assumes that water controls decomposition primarily through water stress (Adair et al. 2008). Although several different temperature functions may be used to calculate CDI (Del Grosso et al. 2005), we used Lloyd and Taylor's (1994) variable $\mathrm{Q}_{10}$ temperature function, because it performs well from arctic to tropical biomes (Adair et al. 2008). This index succinctly summarizes the effect of climate on decomposition at coarse spatial scales and better predicts large-scale patterns of decomposition than indices such as actual or potential evapotranspiration (Del Grosso et al. 2005; Adair et al. 2008).

\section{APPROACH AND EXPERIMENTAL DESIGN}

We used the litterbag method to measure mass loss of two standard substrates (Singh \& Gupta 1977; Harmon et al. 1999), which is easy to implement and thus allows a higher chance of maintaining consistency across multiple observers and sites. The full-factorial experimental design included two litter types, two litterbag mesh sizes and two decomposition environments (above- and below ground). We did not compare rates of leaf litter versus root decomposition; rather, we evaluated how the environment for decomposition of standard substrates varies above- versus below ground. Two sites lacked below-ground treatments: the Hawaiian site, HAW, did not have an appreciable soil layer (substrate of a'a lava with intermittent pockets of soil development); and insufficient sterilized litter was available for the Indonesian site (ULU).

Because we faced import restrictions, we used two commercially available substrates, raffia, Raphia farinifera (Arecaceae), and organic bay leaves, Laurus nobilis (Lauraceae), which are used as craft materials or spices, respectively. These substrates were chosen from 12 possible standards because they differ markedly in initial litter chemistry and physical properties (Table 1), but are 'leaf-like' and have carbon (C) fractions and nitrogen $(\mathrm{N})$ concentrations similar to litters found in tropical forests. Even so, they do not necessarily reflect the full diversity of litter quality or types found in tropical forests.

Initial chemistry was measured in bulk samples as follows: total $\mathrm{C}$ and $\mathrm{N}$ were measured on an automated elemental analyzer (CE Elantech, Lakewood, NJ), total $\mathrm{P}, \mathrm{Ca}, \mathrm{K}$ and $\mathrm{Mg}$ were quantified by

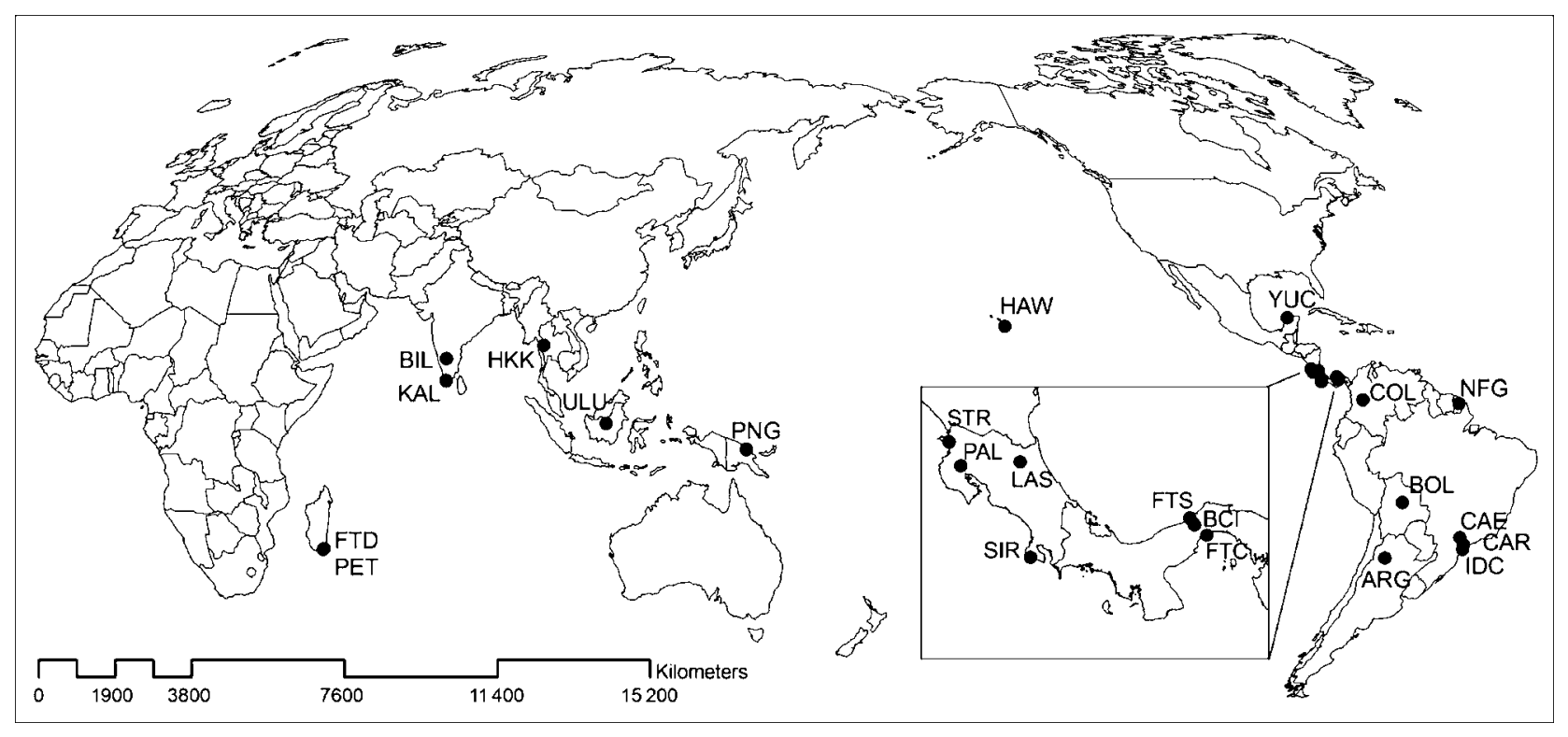

Fig. 1. Location of study sites. Site codes are presented in Table S1.

(C) 2009 The Authors. Journal compilation ( 2009 British Ecological Society, Journal of Ecology, 97, 801-811 
Table 1. Initial litter chemistry and specific leaf area for composite samples of two standard substrates

\begin{tabular}{lcr}
\hline Property & Raffia & Bay \\
\hline Nitrogen (\%) & 0.78 & 1.15 \\
Carbon (\%) & 45.92 & 50.56 \\
P (\%) & 0.12 & 0.10 \\
Mg (\%) & 0.18 & 0.10 \\
Ca (\%) & 0.15 & 1.01 \\
K (\%) & 1.06 & 0.52 \\
Lignin (\%) & 15.57 & 11.41 \\
Total phenolics (\%) & 0.31 & 1.81 \\
C/N & 58.6 & 43.8 \\
Lignin $/ \mathrm{N}$ & 20.0 & 9.9 \\
SLA $\left(\mathrm{cm}^{2} \mathrm{~g}^{-1}\right)$ & 135.5 & 72.4 \\
\hline
\end{tabular}

inductively coupled plasma emission spectroscopy (Perkin Elmer Optima 3000 ICP Spectrometer, Waltham, MA) after dry ashing, acid detergent lignin was measured using an ANKOM Fiber Analyzer (ANKOM Technology, Macedon, NY) and total phenolics were quantified according to the Folin and Ciocalteau method (Folin \& Ciocalteau 1927). Specific leaf area (SLA) was determined in subsamples by dividing dry leaf area by dry weight (measured after drying at $65^{\circ} \mathrm{C}$ for $48 \mathrm{~h}$ ). This approach likely results in slightly underestimated SLA values (usually determined as fresh leaf area) due to shrinkage upon drying. Bay leaves have higher $\mathrm{N}$ concentrations than raffia and lower lignin (Table 1). Two measures of litter quality, $\mathrm{C} / \mathrm{N}$ and lignin/ $\mathrm{N}$, are lower for bay than raffia and bracket the average global $\mathrm{C} / \mathrm{N}$ ratio of $54 \pm 38$ for leaf litter in the tropics (Aerts 1997), but are slightly lower than the average $\mathrm{C} / \mathrm{N}$ for tropical fine roots, $67 \pm 6$ (Silver \& Miya 2001). Based on $\mathrm{C} / \mathrm{N}$ ratios, bay leaves would be expected to decompose faster than raffia. However, bay has approximately four times the phenolic concentrations than raffia and lower SLA, suggesting the opposite trend, that is, that bay should decompose more slowly than raffia (Hättenschwiler \& Vitousek 2000). Both substrates were sterilized using gamma radiation (25-40 kilograys, IBA Steriogenics).

Soil faunal effects were assessed using litterbags with different mesh sizes ( $52 \mu \mathrm{m}$-mesh nylon cloth or 2-mm mesh nylon netting) to selectively exclude or include different components of the decomposer community. The fine mesh allows access by bacteria, fungal hyphae, nematodes and protozoa, while restricting access by mesofauna $(100 \mu \mathrm{m}$ to $2 \mathrm{~mm})$ and macrofauna (>2 mm) (Swift et al. 1979). The coarse mesh allows access by mesofauna such as Acari, Collembola and some earthworms. Because using varying mesh sizes to exclude components of the faunal community may cause indirect or direct experimental artefacts such as altered microclimate (Bradford $e t$ al. 2002b), many studies have used the insecticide naphthalene to reduce faunal densities (Seastedt 1984; Wall et al. 2008). However, it is likely that naphthalene would have rapidly leached away in our high rainfall sites, confounding the effects of faunal treatment and climate.

Litterbags $(10 \times 15 \mathrm{~cm})$ were filled with $1.00 \pm 0.01 \mathrm{~g}$ dry sterilized substrate (raffia fibres were cut into $5-7 \mathrm{~cm}$ pieces and bay leaves were whole or cut in half), sealed with rust-proof staples, tied together and shipped to each collaborator for deployment. Two stakes were placed approximately $13 \mathrm{~m}$ apart (hereafter referred to as plots 1 and 2) on level ground. Ten strings of bags (6 bags each) were tied to each stake and arranged in a radial pattern from the centre. Strings of above-ground bags were anchored to the surface of mineral soil (after scraping away any organic layer) with a wire 'wicket' to minimize disturbance. Strings of below-ground bags were interspersed between the above-ground bags. They were buried in mineral soil (10-15 cm deep) at an approximately $45^{\circ}$ angle by using a small spade to slice through the soil, gently sliding in the bag, and replacing the divot on top of the bag.

Bags were placed in the field at the start of the wet season in each site, or when it was convenient at sites without wet seasons (LAS and HAW) during 2002, 2003 and 2005 (ULU only). Subsets of bags were collected approximately 1, 3, 5, 7 and 9 months after placement. Following retrieval, each bag was opened, contents were removed and soil particles, extraneous debris, or roots clinging to the litter substrates were removed with tweezers. Samples were gently washed in tap water to remove adhering soil particles, dried at 50$55^{\circ} \mathrm{C}$ until constant weight, and weighed to $\pm 0.01 \mathrm{~g}$. There were three replicates per treatment and collection date (divided between two plots per site), for a total of 2640 litter bags (of which we recovered 2571).

\section{CALCULATIONS AND STATISTICAL ANALYSES}

We calculated first-order exponential decay coefficients ( $k$ values in units of year $\left.{ }^{-1}\right)$ as the slopes of linear regressions of the natural logarithm of percent mass remaining versus time (Olson 1963; Wieder \& Lang 1982) for each combination of plot, site and treatment. Y-intercepts were forced through $100 \%$ mass remaining at time 0 , and all zero values (i.e. complete decomposition) were set to $0.01 \%$ mass remaining prior to calculating natural logs. The sample size used to estimate $k$ varied among site and plot (from 5 to 10) because of differences in the number of bags initially deployed and because some bags were not recovered (e.g. some were penetrated by coarse roots, stolen, too covered in soil for adequate weight determination or completely destroyed by insect activity). In general, the first order decay models fit the data well (Appendix S1 in Supporting Information): of the 352 regressions, 172 had $R^{2}$ values $>0.75$ and 300 had $R^{2}>0.50 . k$ values, degrees of freedom, $R^{2}$ and $P$-values for each regression appear in Appendix S1. For ease of interpretation, we present the absolute values of the slopes, that is, low $k$ values indicate slow decomposition rates.

Long-term litter decomposition studies often reveal a two-phase pattern of mass loss, in which an initial, rapid stage of decomposition is followed by a longer, slower stage (Wieder \& Lang 1982). This pattern is attributed to quick decomposition of labile substrates such as carbohydrates, which are depleted early, followed by slower decay of chemically complex, recalcitrant substrates (e.g. lignin) (Melillo et al. 1989). We compared the fit of one- and two-pool models to each site by treatment combination using the nonlinear regression and model comparison methods described in Adair et al. (2008) (Proc NLIN, SAS 9.1, SAS Institute, Inc.). One-pool models fit our data as well as or better than two-pool models for $91 \%$ of the cases (data not shown). Given the overall better fit of the one-pool models and to compare across site and treatment combinations, we restricted statistical analyses to the one-pool $k$ values from linear regressions.

We used ANOVA to test the individual and interactive effects of site, litter type, above- or below-ground environment, and litterbag mesh size (mesofaunal community) on decay rates (Splus Version 8.0, Insightful Corp.). The ANOva was unbalanced because two sites (HAW, ULU) lacked below-ground litterbags. The response variable decay rate $(k)$ was log-transformed prior to analysis to meet assumptions of homogeneity of variance. Type III Sums of Squares were used to assess significance of main effects and interactions. 
Stepwise, linear regression with a backward and forward selection procedure was used to explore the relationships between $k$ values and climate (Splus Version 8.0, Insightful Corp.). First, we ran a regression analysis with $k$ averaged over all treatments at each site using MAT, MAP, CDI and DSL as predictor variables. This analysis produces a final model that includes the predictor variables that best explain variation among sites, and discards variables with no additional explanatory power. No data transformations were needed. Second, we explored how the effect size of individual treatments varied across climatic gradients. We calculated estimates of individual treatment effect sizes (i.e. litter type, environment and fauna) at each site as the ratio of litter decay rates for contrasting treatments, averaging over all other treatments within a site. We then ran three separate stepwise regression analyses with litter type effect (bay/raffia), environment effect (above-/below ground) and mesofaunal effect (mesofauna present/mesofauna excluded) as response variables, and MAT, MAP, CDI and DSL as predictor variables. ULU was excluded for lack of temperature data. Certain analyses were re-run excluding HAW, PNG and/or SIR (see Discussion).

\section{Results}

\section{DECOMPOSITION RATES AND TREATMENT EFFECTS}

Decay rates ranged from 0.47 year $^{-1}$ for raffia decomposing above ground without mesofauna in a dry forest in Thailand (HKK), to 15.10 year $^{-1}$ for bay leaves decomposing above ground with mesofauna in a wet forest in Papua New Guinea (PNG). Mean $k$ among sites and treatments was 3.08 year $^{-1}$ (Fig. 2). Two sites stood out as having anomalous decay rates: HAW, which had exceptionally low $k$ values despite a MAP of $3600 \mathrm{~mm}$, and PNG, which had the largest range of $k$ values and the highest values. We suspect that these sites are outliers for different reasons (see Discussion).
Table 2. Results from ANOva with decay rate ( $\log _{10}$-transformed) as the response variable, and site (S), above- or below-ground environment (E), litter type (L) and fauna treatment (F) as explanatory variables

\begin{tabular}{lrllll}
\hline Factor & d.f. & Type III SS & Mean square & $F$ & $P$-value \\
\hline Site & 22 & 18.64 & 0.85 & 31.18 & $<0.00001$ \\
Environment & 1 & 1.00 & 1.00 & 36.78 & $<0.00001$ \\
Litter type & 1 & 3.00 & 3.00 & 110.41 & $<0.00001$ \\
Fauna & 1 & 5.42 & 5.42 & 199.56 & $<0.00001$ \\
S:E & 20 & 2.06 & 0.10 & 3.79 & $<0.00001$ \\
S:L & 22 & 1.24 & 0.06 & 2.07 & 0.005 \\
E:L & 1 & 0.02 & 0.02 & 0.61 & 0.43 \\
S:F & 22 & 1.72 & 0.08 & 2.88 & 0.0006 \\
E:F & 1 & 0.02 & 0.02 & 0.88 & 0.35 \\
L:F & 1 & 0.01 & 0.01 & 0.35 & 0.56 \\
S:E:L & 20 & 0.46 & 0.02 & 0.85 & 0.65 \\
S:E:F & 20 & 0.73 & 0.04 & 1.35 & 0.15 \\
S:L:F & 22 & 0.88 & 0.04 & 1.47 & 0.09 \\
E:L:F & 1 & 0.02 & 0.02 & 0.81 & 0.37 \\
S:E:L:F & 20 & 0.74 & 0.04 & 1.41 & 0.15 \\
Residuals & 176 & 4.78 & 0.03 & & \\
\hline
\end{tabular}

Fauna presence/absence, litter type, decomposition environment and site all had large, significant effects on decay rates (Table 2). Based on $F$-ratios, mesofaunal presence/absence had the largest effect on decomposition compared to other treatments, with mesofaunal absence resulting in similar or lower decay rates than mesofauna presence at all sites (Fig. 3c). All second-order interactions among treatments and the variable site were significant $(P<0.005)$, indicating that how litter type, litter placement or mesofauna affected litter decay rates depended upon site. However, the low $F$ ratio of the site by fauna interaction (2.88) indicated that the
Fig. 2. Box plots depicting median (centre lines), upper and lower quartile ranges (edges of boxes) and extremes (upper and lower whiskers) of decay rates $(k)$ for different treatment combinations grouped by site (outliers are 1.5 times the interquartile range). Sample sizes are $N=16$ for all sites except HAW and ULU $(N=8)$. Site codes are presented in Table $\mathrm{S} 1$.

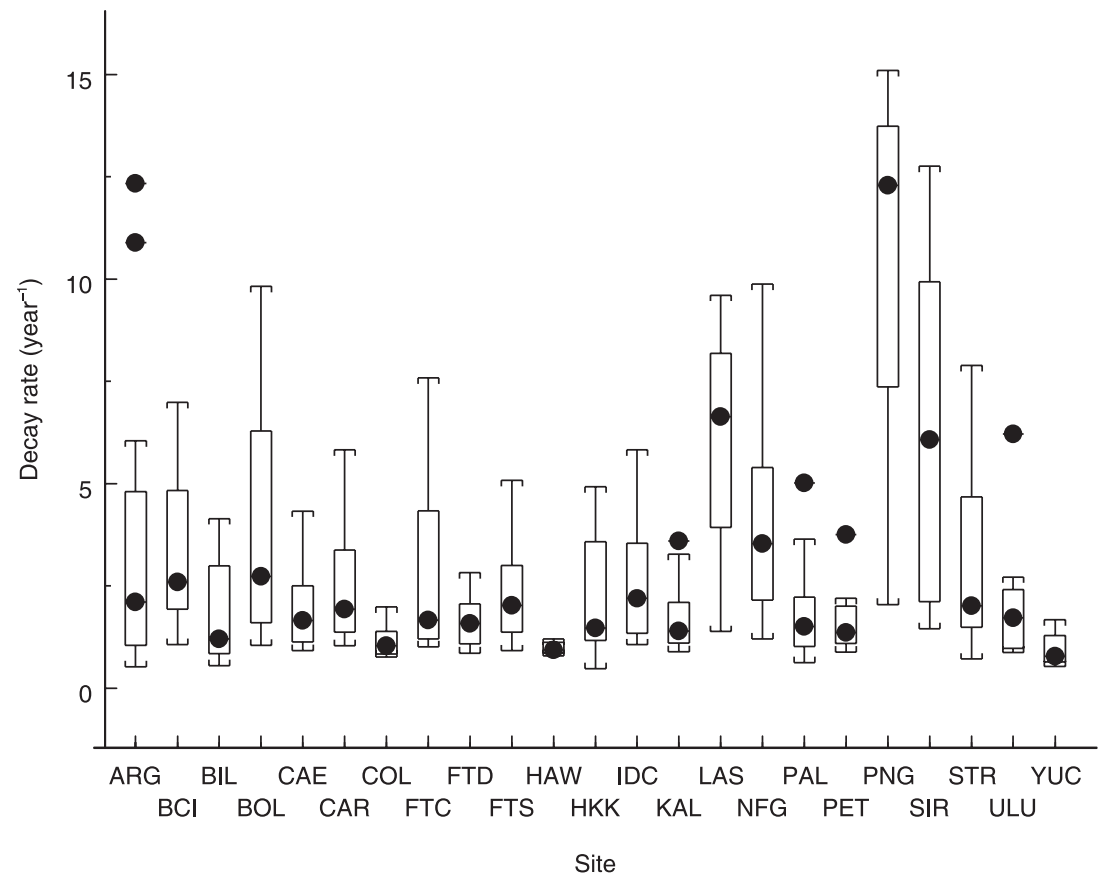

(C) 2009 The Authors. Journal compilation (C 2009 British Ecological Society, Journal of Ecology, 97, 801-811 

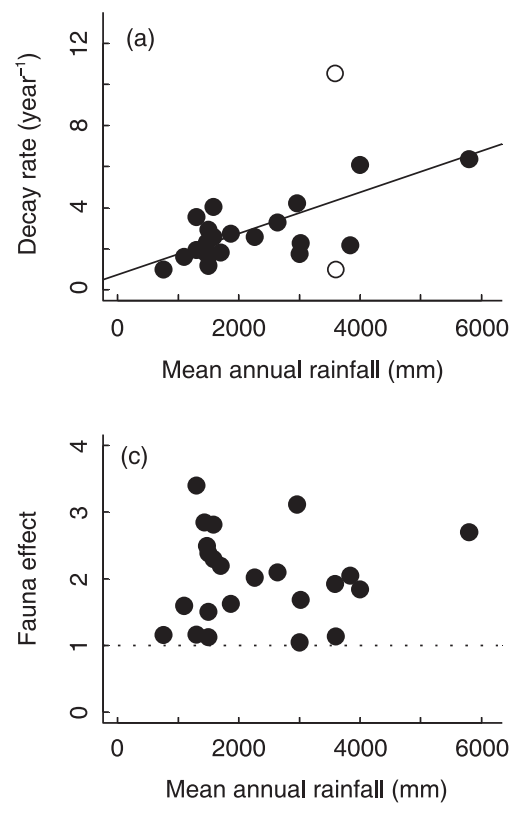
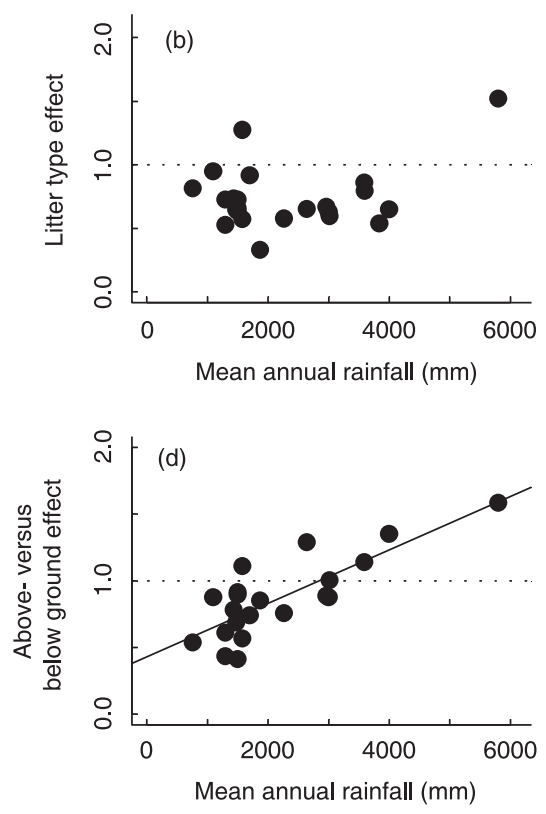

Fig. 3. Mean decomposition rate $(k)$ averaged over all treatments for 23 tropical forest sites (a) as a function of mean annual precipitation (MAP), where the solid line refers to regression of $k$ on MAP $\left(R^{2}=0.60\right)$, excluding HAW and PNG (open circles); (b) averaged by litter type effect, that is, the ratio of $k$ values for bay/raffia averaged over all other treatments at each site, where the dashed line indicates no treatment effect; (c) averaged by fauna effect, that is, the ratio of $k$ values for litter decomposing in coarse- versus fine-mesh bags averaged over all other treatments at each site, where the dashed line indicates no treatment effect; and (d) averaged by the effect of environment of litter placement, that is, the ratio of $k$ values for litter decomposing aboveversus below ground, averaged over all other treatments at each site, where the solid line refers to regression on MAP $\left(R^{2}=0.65\right)$ and the dashed line indicates no treatment effect.

Table 3. Results from stepwise multiple regression analyses relating site-averaged decay rates and ratios of treatment effects to climatic variables. Initial models included MAT, MAP, DSL and the CDI. All analyses were run twice: once with the full dataset (22 sites, excluding ULU) and again omitting HAW and PNG, which were apparent outliers. The environment effect could not be estimated for HAW and ULU because it lacked below-ground bags

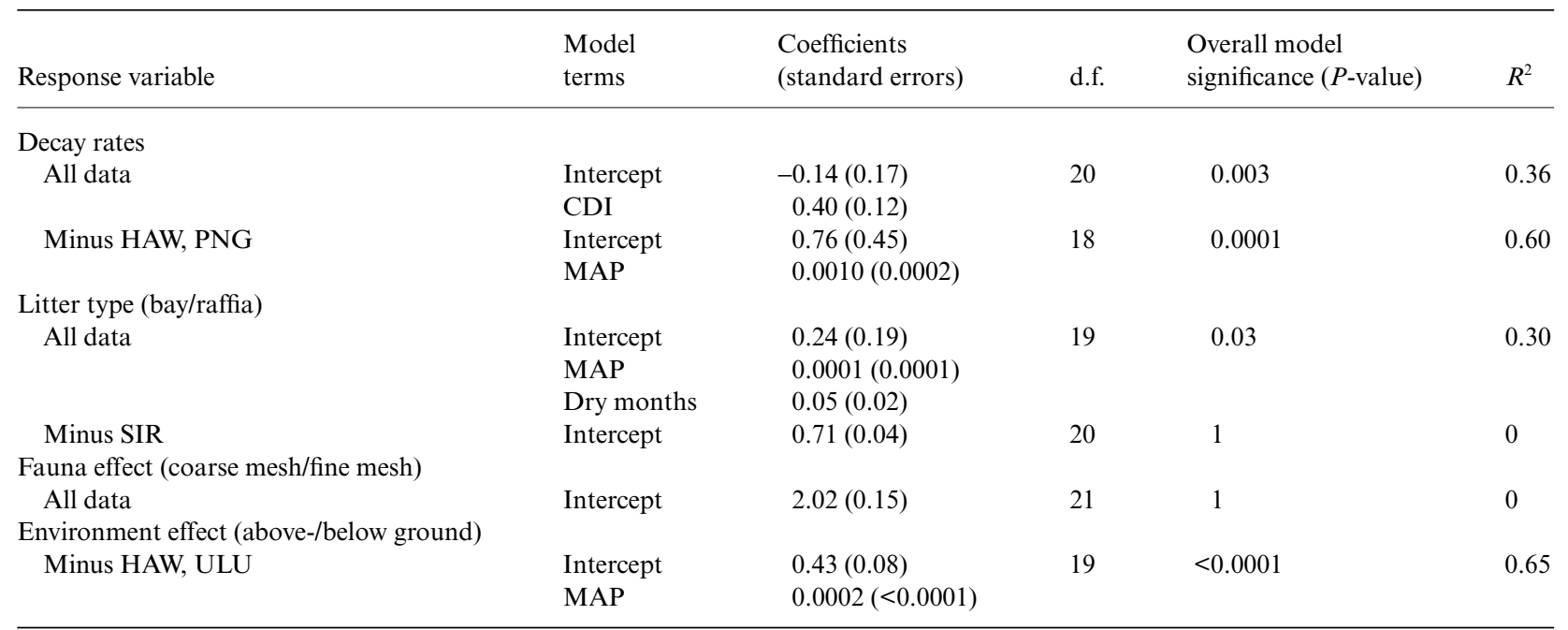

effect of mesofauna was only slightly modified by local site conditions. No other second-, third- or fourth-order interaction terms had significant effects on decay rates (Table 2). When the putative outliers HAW and PNG were excluded, similar results were obtained, that is, all main effects and pairwise interactions involving the variable site were statistically significant $(P<0.002$; results not shown).

\section{RELATIONSHIPS WITH CLIMATE}

Of the four climate variables, the CDI was the best predictor of average $k$, explaining $36 \%$ of the variation among sites (Table 3). However, when HAW and PNG were omitted,
MAP was a better predictor of $k\left(R^{2}=0.60\right.$; Table 3, Fig. 3a). Stepwise regression revealed that DSL and MAT explained no additional variation in the full or restricted data sets (omitting HAW and PNG).

On average, bay leaves decomposed at approximately $75 \%$ of the rate that raffia did (Fig. 3b). The significant, positive relationship between the ratio of bay/raffia decomposition rates and MAP was driven largely by the site with the largest MAP (Fig. 3b), SIR, as this relationship disappeared when this site was omitted from the analysis (Table 3). Across all sites, litter types and above- or below-ground environments, decay rates were approximately twice as high in coarse-mesh bags that allowed mesofauna access than fine-mesh bags that 
excluded mesofauna (Fig. 3c). The magnitude of this effect did not depend on any of the climatic variables (Table 3 ). Finally, the ratio of above- versus below-ground decomposition rates increased linearly with MAP (Fig. 3d; Table 3). Litter decomposed faster below ground in sites with approximately $<3000$ mm MAP; conversely, litter decomposed faster above ground in wetter forests. None of the multiple regression models for litter type, fauna or litter environment differed appreciably when HAW and PNG were excluded from the analyses (results not shown).

Plotting $k$ by MAP separately for each treatment combination revealed that above-ground treatments were most responsible for the positive relationship between MAP and average $k$ (Fig. S1), although the slope of this relationship was greater for litterbags decomposing with mesofauna compared to without (Fig. S1). For litterbags decomposing below ground, there were significant relationships between $k$ and MAP for bay but not raffia (Fig. S1).

\section{INTRA-SITE VARIATION}

In addition to large inter-site variation in decomposition rates and treatment magnitudes, the ranges of decomposition rates within sites varied considerably (Fig. 2). We tested whether intra-site variation was related to rainfall or treatment effect size of by plotting measures of within-site variation against MAP and treatment effect. Standard deviations of decay rates across all treatment combinations increased with MAP $(r=$ $0.46, P=0.03$, results not shown), but the coefficient of variation $(\mathrm{CV})$, which is standardized by the site mean value, was not related to MAP $(P=0.60$; Fig. $4 \mathrm{a})$. $\mathrm{CVs}$ were neither related to the litter type effect $(P=0.96$; Fig. $4 \mathrm{~b})$ nor to environment effects $(P=0.09$; Fig. 4 d), but did increase linearly with the mesofaunal effect ( $r=0.77, P<0.0001$; Fig. $4 \mathrm{c}$ ).

\section{Discussion}

In our worldwide experiment in tropical forests, the average short-term litter decay rate across sites and treatments was 3.08 year $^{-1}$, indicating that $95 \%$ of litter decomposed in 1 year. Not surprisingly, this rate is higher than values reported from temperate forests (Gholz et al. 2000), but is similar to the mean value of 2.27 (range $0.5-3.8$ ) reported for 14 tropical lowland moist forests (Anderson \& Swift 1983) and is slightly higher than long-term decomposition rates from five Neotropical forests (Cusack et al. 2009). However, the average observed decay rate conceals a ten-fold variation among sites (Fig. 2), as well as considerable variation within sites. What accounts for this large variation? All of the factors we investigated had strong, independent effects on decomposition rates, but the magnitudes of these effects were site-specific (Table 2), as were the decay rates themselves.

\section{SITE AND CLIMATE EFFECTS}

Decomposition rates and the effects of our treatments differed among sites. There are at least three factors that may explain the strong site effect: observer, climate, or site factors that we did not measure (e.g. soil fertility or fauna abundance and diversity). Even though we used standardized protocols, observer bias may have contributed to variation among sites. This effect is likely to be minimal in our study because in many cases a single observer or team often handled multiple sites. We are confident that observer bias is not a large factor influencing our results at most sites, but decomposition rates may have been overestimated at PNG, where we recorded many zeros, especially in collection dates that occurred early in the experiment. Excluding PNG from analyses changed the magnitude of estimated effects, but not the conclusions or
Fig. 4. Coefficients of variation for decay rates within sites plotted as a function of (a) mean annual precipitation, (b) litter type effect, (c) fauna effect and (d) environment effect, that is, above versus below ground (each point refers to a site).
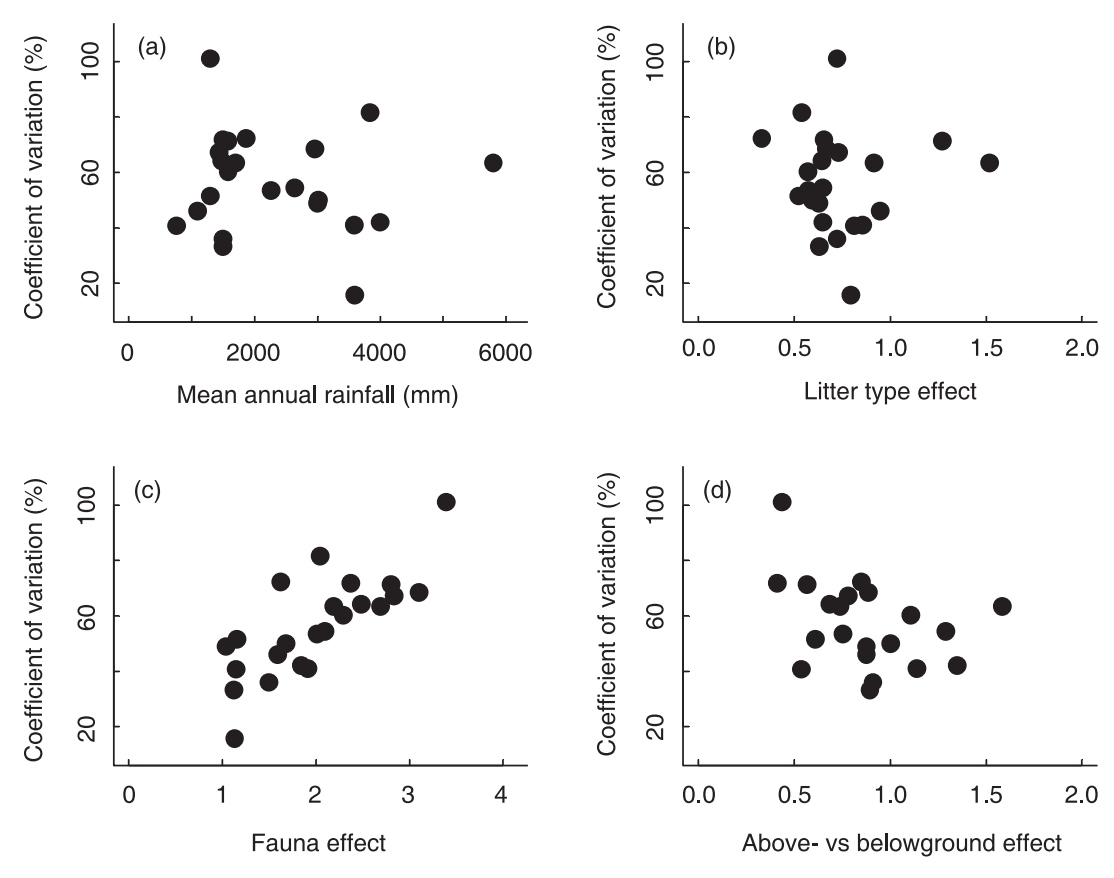
inferences drawn from the data. In contrast, HAW, which had low decay rates despite high MAP, may be an outlier for biological reasons. This forest was located on a young lava flow with very little soil development, and it is likely that soil moisture was low despite high rainfall.

Previous work using similar methods has shown that temperature controls decomposition across large climatic zones in temperate and boreal forests (Berg et al. 1993; Gholz et al. 2000; Trofymow et al. 2002). In contrast, precipitation is one of the most important drivers of decomposition in our tropical sites. After excluding the putative outliers PNG and HAW, the positive, linear relationship between MAP and decay rates accounted for $60 \%$ of the variation in average decomposition rate among sites, whereas MAT, DSL or CDI explained little or no additional variation. Above-ground treatments were largely responsible for these patterns (belowground decay rates were only weakly related to climate) (Fig. S1). Our finding that precipitation controls decomposition in tropical forests with similar temperature regimes is thus consistent with existing theory, but our dataset adds considerable detail on the role of fauna, litter type, and the environment (above-/below ground) for decomposition.

It is remarkable that such a simple climate index explained such a large portion of the variation in decay rates among sites, especially considering that the MAP values are long-term averages and do not necessarily reflect the exact weather conditions at the time of the experiment. Moreover, the CDI, which incorporates both temperature and moisture, did not explain more variation than precipitation. This may result from the small temperature range among sites, but may also result from CDI being calculated from interpolated climate data from a global database, rather than from site-specific sources. Precipitation can have direct effects on decomposition via effects on microbial activity, mesofaunal abundance and diversity, and/or leaching of soluble compounds, or indirect effects mediated by changes in plant traits and litter chemistry (Fragoso \& Lavelle 1992; Cornejo et al. 1994; Austin \& Vitousek 2000). Many of the comparative studies of the effects of precipitation on decomposition in tropical ecosystems come from Hawaii (Vitousek et al. 1994; Austin \& Vitousek 2000; Schuur et al. 2001). Similar to our findings, one study of sites with the same MAT and soil age found that decay rates increased linearly with MAP across a large precipitation gradient on the island of Hawaii (500-5500 mm MAP) (Austin \& Vitousek 2000). In contrast to other studies, we found no evidence for inhibition of decomposition at high rainfall, which might occur due to anaerobic conditions (Schuur 2001).

Our forests likely differ from one another in many other ways besides climate. Differences in soil fertility and the community composition of plants, microorganisms and fauna may explain some of the variation in decomposition within and among our sites that was not explained by rainfall. Studies of leaf and root decomposition across a natural soil fertility gradient suggest that decomposition rates increase with soil nutrient availability (Ostertag \& Hobbie 1999; Hobbie \& Vitousek 2000). However, the strongest effect of soil nutrient availability on decomposition may be an indirect one, mediated by nutrient and lignin composition of plant tissues (Hobbie \& Vitousek 2000). Rainfall also often correlates negatively with soil fertility in tropical forests (Clinebell et al. 1995; i.e. wetter forests have higher leaching rates), but because we do not have measures of nutrient availability for our sites, we cannot partition the effects of MAP on decomposition into direct effects due to water availability versus indirect effects mediated by soil fertility. Irrespective of the exact mechanisms, our data provide strong support for a direct or indirect causal relationship between precipitation and decomposition rates that may be useful in efforts to model decomposition rates across tropical ecosystems.

\section{FAUNAL EFFECTS}

Consistent with other studies (Edwards \& Heath 1963; Anderson \& Swift 1983; Seastedt 1984), our study underscores the importance of the faunal community for decomposition. Of all our treatments, excluding mesofauna had the largest impact on decomposition, halving rates on average (Fig. 3), and this overwhelming importance was only slightly modified by local site conditions. Thus, mesofaunal activity is a major driver of decomposition in these forests (Table 3) and is largely independent of precipitation (Fig. 3c). We caution that our interpretations of these results are based on excluding fauna $>2 \mathrm{~mm}$, and it is possible that larger fauna may affect rates of comminution, abundances of smaller organisms or other processes. However, a litterbag study in a wet forest in Mexico found no difference in decay rates between 1 and 6-mm mesh bags for two litter types, suggesting a similar role for fauna between 1 and 6 mm (Barajas-Guzmán \& AlvarezSánchez 2003).

The magnitude of the effect of excluding soil fauna did not depend on rainfall, in contrast to a study that included both low and high latitude ecosystems (Wall et al. 2008). At least three, non-mutually exclusive possibilities may explain this discrepancy. First, the relationship between faunal diversity or abundance and precipitation may be complex, such that the effects of faunal exclusion on decomposition may not be a simple, monotonic function of precipitation. The abundance and diversity of soil and litter earthworms in tropical forests have been shown to vary across precipitation and soil fertility gradients (Fragoso \& Lavelle 1992). Earthworms account for the largest fraction of soil and litter meso- and macrofaunal biomass in tropical forests compared with termites, Coleoptera, Myriapoda, ants, spiders, Isopoda, and Diptera, and their biomass and density show a unimodal relationship across a $1280-5700 \mathrm{~mm}$ range of MAP with highest values at approximately $3000 \mathrm{~mm}$ MAP (Fragoso \& Lavelle 1992). Anderson and Swift (1983) suggested that communities of organisms at each site are highly dynamic and to some extent redundant, such that when one component is removed, another group compensates (Anderson \& Swift 1983). They argued that that this flexibility impedes the 'predictive value' of the role of fauna in decomposition studies; thus the function of faunal communities may not be predicted 
from patterns of abundance and diversity alone, and, by extension, from simple climate indices like MAP.

A second mechanism that might explain our results is the interaction between rainfall and fauna. Low rainfall or temperature likely limits the activity of soil fauna (Wall et al. 2008) up to a particular threshold, beyond which increasing amounts of rainfall or temperature may no longer affect the relationship of faunal exclusion to decomposition. Our sites are comparatively warm and wet, and it is possible that soil fauna are not limited by moisture during the wet seasons even at our driest sites. For example, in one of our drier sites $($ MAP $=1500 \mathrm{~mm})$, no litter decomposition occurs during the dry season, but some species can lose up to $35 \%$ of initial mass in the first 2 weeks following the start of the wet season (Powers, unpublished data).

While our data do not allow us to discriminate whether faunal effects are due to community composition, abundance or other factors, the linear correlation between the mesofaunal exclusion effect and the coefficient of variation (Fig. 4c) suggests a final possibility. Strong faunal effects may only occur in sites with large intra-site variation, but not necessarily fast decomposition rates.

In summary, our results suggest a large role for soil fauna in controlling decomposition in tropical forests, but this effect is not necessarily predicted by rainfall. One implication of this finding is that any particular 'wet' versus 'dry' forest comparison might suggest a unique, but unrepresentative conclusion regarding the role of fauna on decomposition, whereas our precipitation gradient helped reveal the complexity of the patterns. To fully understand the contribution of fauna to decomposition in tropical forests, we need to investigate other factors such as diversity and abundance, which in turn may be influenced by factors such as soil fertility, trophic interactions, and evolutionary history.

\section{THE ENVIRONMENT FOR DECOMPOSITION}

Studies comparing root and leaf litter decomposition across rainfall gradients in Hawaii have found stronger changes in decomposition rates for leaves than roots (Schuur 2001). Because we decomposed the same substrates both aboveand below ground, our study provides insights into how the environmental conditions for decomposition vary aboveversus below ground, but does not directly compare leaf versus root decomposition. As predicted, substrates decomposed faster below ground in the drier forests and faster above ground in forests with MAP approximately $>3000 \mathrm{~mm}$ (Fig. 3d). This pattern was largely driven by the significant relationships between above-ground decomposition and MAP, compared to below-ground decomposition, which varied less across the rainfall gradient (Fig. S1). Even though root decomposition may be affected by a complex suite of variables including soil texture, which affects soil water holding capacity (Gijsman et al. 1997), the strong, linear relationship between MAP and the ratio of above- to belowground decomposition may be generalizable across tropical forests.

\section{LITTER TYPE EFFECTS}

Simple chemical variables, such as N concentration or lignin/ $\mathrm{N}$ ratio, are commonly the best predictors of decomposition rate when different litters are decomposed in the same environment (Singh 1969; Hobbie 2005; Santiago 2007; Cornwell et al. 2008; Kurokawa \& Nakashizuka 2008). We chose two standard 'leaf-like' substrates that bracket the range of litter quality indices for tropical forests, but we emphasize that they do not cover the full range of litter chemistry found in the many tree species of tropical forests. Although litter type affected decomposition rate, which substrate decomposed faster depended upon site (Fig. 3b). This significant interaction contrasts with other researchers investigating decomposition of multiple litter types in Argentina and the UK, who have found that the rank order of decomposition rates is the same among sites (Cornelissen et al. 1999). Other studies have shown an interaction between litter chemistry and climate, with litter chemistry having larger effects on decay rates in sites with more favourable climates for decomposition (i.e. higher AET) (Meentemeyer 1978), but because we only used two litter types, it is difficult to draw similar conclusions from our data.

At most of our sites, bay leaves decomposed slower than raffia, despite having higher $\% \mathrm{~N}$ and lower lignin/N. In our study, the chemical and structural properties of the two substrates were orthogonal, that is, bay has high $\% \mathrm{~N}$ with low SLA, and raffia has low $\% \mathrm{~N}$ with high SLA. For these two standard litter substrates, physical traits appear to control decomposition more than chemical properties like $\% \mathrm{~N}$. In particular, after several months of incubation in the field, raffia appeared more friable and fragmented (J. Powers et al., personal observation). Other studies support the role of physical traits and secondary compounds in decomposition: structural properties of leaves such as toughness (Gallardo \& Merino 1993), SLA (Cornelissen 1996) or compounds such as polyphenols (water soluble molecules with aromatic rings, as opposed to insoluble complexes such as lignin) (Hättenschwiler \& Vitousek 2000), correlate with decomposition (Horner et al. 1988).

\section{Conclusion}

A key goal of ecology is to discover patterns across ecosystems and identify the mechanisms underlying these patterns. Responding to global environmental change requires both site-specific understanding and integration at the regional- to continental-scale. Field studies such as ours directly inform global biogeochemical models in several ways: they are useful for developing theory, parameterizing and validating models, and suggesting avenues for model improvement (Moorhead et al. 1999). Our study corroborates previous studies showing that simple climatic variables are good predictors of decomposition rates across large gradients (Gholz et al. 2000; Trofymow et al. 2002; Liski et al. 2003), but also provides evidence for site-specific factors that are difficult to generalize among sites. In lowland tropical forests where temperatures 
are high year round, decomposition rates of standard substrates were linearly related to annual precipitation, especially for litter decomposing above ground. Moreover, precipitation also affected the environment for decomposition, such that in drier forests decomposition was faster below ground, but in wetter forests it was faster above ground. However, we found no linear relationship between precipitation and the effect of faunal exclusion. Instead, we found large, site-specific effects of the mesofaunal community on decomposition rates in 23 tropical forests, suggesting that, while studies of effects of the decomposer communities may uncover important processes or mechanisms of decomposition at a particular site, it may be difficult to generalize to other tropical forests.

\section{Acknowledgements}

This study was funded by a Comparative Tropical Biology Fellowship to J.S.P. and R.A.M. from the Organization for Tropical Studies funds from the Mellon Foundation to M.T.L. and an NSF ADVANCE Fellowship (DBI-0338143) to J.S.P. We thank Marie Tiffin and Tom Savre for helping to fill litter bags and Janneke HilleRisLambers and Kit Bingham for statistical advice. Many thanks go to Justin Becknell for preparing the map of the sites. Many people from all over the world helped with data collection, and we thank them all: Brus Isua of New Guinea Binatang Research Center, Ana Horta in Argentina, Rebecca Ostertag at University of Hawaii at Hilo, Rivo A. Rajoharison of QMM (Madagascar), G. Vanaraj at ATREE (Bangalore, India), Kursani of Project Barito Ulu (Indonesia), Marco Vinisio Martínez at Pontificia Universidad Javeriana (Bogotá, Colombia), and Gerardo Polanco Hernández in CICY, Yucatán (Mexico). We thank the Karnataka and Tamil Nadu Forest Departments for permission to work in BIL and KAL, and MINAE for permission to work in LAS, STR, PAL and SIR. We especially thank two anonymous referees, Peter Tiffin and Hans Cornelissen for comments that improved this manuscript.

\section{References}

Adair, E.C., Parton, W.J., Del Grosso, S.J., Silver, W.L., Harmon, M.E., Hall, S.A., Burke, I.C. \& Hart, S.C. (2008) Simple three-pool model accurately describes patterns of long-term litter decomposition in diverse climate. Global Change Biology. 14, 2636-2660.

Aerts, R. (1997) Climate, leaf litter chemistry and leaf litter decomposition in terrestrial ecosystems: a triangular relationship. Oikos, 79, 439-449.

Anderson, J.M. \& Swift, M.J. (1983) Decomposition in tropical forests. Tropical Rain Forest: Ecology and Management (eds S.L. Sutton, T.C. Whitmore \& A.C. Chadwick), pp. 287-309. Blackwell Scientific Publications, Oxford.

Austin, A.T. \& Vitousek, P.M. (2000) Precipitation, decomposition and litter decomposability of Metrosideros polymorpha in native forest on Hawai'i. Journal of Ecology, 88, 129-138.

Barajas-Guzmán, G. \& Alvarez-Sánchez, J. (2003) The relationships between litter fauna and rates of litter decomposition in a tropical rain forest. Applied Soil Ecology, 24, 91-100.

Berg, B., Berg, M.P., Pottner, P., Box, E., Breymeyer, A., Calvo de Anta, R., et al. (1993) Litter mass loss rates in pine forests of Europe and Eastern United States: some relationships with climate and litter quality. Biogeochemistry, 20 127-159.

Bradford, M.A., Jones, T.H., Bardgett, R.D., Black, H.I.J., Boag, B., Bonkowski, M., et al. (2002a) Impacts of soil faunal community composition on model grassland ecosystems. Science, 298, 615-618.

Bradford, M.A., Tordoff, G.M., Eggers, T., Jones, T.H. \& Newington, J.E. (2002b) Microbiota, fauna, and mesh size interactions in litter decomposition. Oikos, 99, 317-323.

Clark, D.A. (2007) Detecting tropical forests' responses to global climatic and atmospheric change: current challenges and a way forward. Biotropica, 39, 4-19.

Clinebell, R.R., Phillips, O.L., Gentry, A.H., Stark, N. \& Zuuring, H. (1995) Prediction of neotropical tree and liana species richness from soil and climatic data. Biodiversity and Conservation, 4, 56-90.

Cornejo, F.H., Varela, A. \& Wright, S.J. (1994) Tropical forest litter decomposition under seasonal drought: nutrient release, fungi and bacteria. Oikos, 70, 183-190.
Cornelissen, J.H.C. (1996) An experimental comparison of leaf decomposition rates in a wide range of temperate plant species and types. Journal of Ecology, 84, 573-582.

Cornelissen, J.H.C., Pérez-Harguindeguy, N., Díaz, S., Grime, J.P., Marzano, B., Cabido, M., Vendramini, F. \& Cerabolini, B. (1999) Leaf structure and defence control litter decomposition rate across species and life forms in regional floras on two continents. New Phytologist, 143, 191-200.

Cornwell, W.K., Cornelissen, J.H.C., Amatangelo, K., Dorrepaal, E., Eviner, V.T., Godoy, O., et al. (2008) Plant species traits are the predominant control on litter decomposition rates within biomes worldwide. Ecology Letters, 11, 1065-1071.

Coûteaux, M.M., Bottner, P. \& Berg, B. (1995) Litter decomposition, climate and litter quality. Trends in Ecology and Evolution, 10, 63-66.

Cusack, D.F., Chou, W.W., Yang, W.H., Harmon, M.E. \& Silver, W.L. (2009) Controls on long-term root and leaf litter decomposition in neotropical forests. Global Change Biology, 15, 1339-1355.

Del Grosso, S.J., Parton, W.J., Mosier, A.R., Holland, E.A., Pendall, E., Schimel, D.S. \& Ojima, D.S. (2005) Modeling soil $\mathrm{CO}_{2}$ emissions from ecosystems. Biogeochemistry, 73, 71-91.

Dewar, R.E. \& Wallis, J.R. (1999) Geographical patterning in intraannual rainfall variability in the tropics and near tropics: an L-moments approach. Journal of Climate, 12, 3457-3466.

Edwards, C.A. \& Heath, G. (1963) The role of soil animals in breakdown of leaf material. Soil Organisms (eds J. Doeksen \& J. vander Drift), pp. 75-84. North Holland Publishing Company, Amsterdam.

Folin, O. \& Ciocalteau, V. (1927) On tyrosine and tryptophane determination in proteins. Journal of Biological Chemistry, 27, 627-650.

Fragoso, C. \& Lavelle, P. (1992) Earthworm communities of tropical rain forests. Soil Biology and Biochemistry, 24, 1397-1408.

Gallardo, A. \& Merino, J. (1993) Leaf decomposition in two Mediterranean ecosystems of Southwest Spain: influence of substrate quality. Ecology, 74, $152-161$.

Gholz, H.L., Wedin, D.A., Smitherman, S.M., Harmon, M.E. \& Parton, W.J. (2000) Long-term dynamics of pine and hardwood litter in contrasting environments: toward a global model of decomposition. Global Change Biology, 6, 751-765.

Gijsman, A.J., Alarcon, H.F. \& Thomas, R.J. (1997) Root decomposition in tropical grasses and legumes, as affected by soil texture and season. Soil Biology and Biochemistry, 29, 1443-1450.

González, G. \& Seastedt, T.R. (2001) Soil fauna and plant litter decomposition in tropical and subalpine forests. Ecology, 82, 955-964.

Harmon, M., Nadelhoffer, K. \& Blair, J. (1999) Measuring decomposition, nutrient turnover, and stores in plant litter. Standard Methods for Long-term Ecological Research (eds G. Robertson, C. Bledsoe, D. Coleman \& P. Sollins), pp. 202-240. Oxford University Press, New York.

Hättenschwiler, S. \& Vitousek, P.M. (2000) The role of polyphenols in terrestrial ecosystem nutrient cycling. Trends in Ecology and Evolution, 15, 238-243.

Hijmans, R.J., Cameron, S.E., Parra, J.L., Jones, P.G. \& Jarvis, A. (2005) Very high resolution interpolated climate surfaces for global land areas. International Journal Climatology, 25, 1965-1978.

Hobbie, S.E. (2005) Contrasting effects of substrate and fertilizer on the early stages of litter decomposition. Ecosystems, 8, 644-656.

Hobbie, S.E. \& Vitousek, P.M. (2000) Nutrient limitation of decomposition in Hawaiian forests. Ecology, 81, 1867-1877.

Horner, J.D., Gosz, J.R. \& Cates, R.G. (1988) The role of carbon-based plant secondary metabolites in decomposition in terrestrial ecosystems. American Naturalist, 132, 869-883.

Kurokawa, H. \& Nakashizuka, T. (2008) Leaf herbivory and decomposability in a Malaysian tropical rain forest. Ecology, 89, 2645-2656.

Lavelle, P., Blanchart, E., Martin, A., Martin, S., Spain, A., Toutain, F., Barois, I. \& Schaefer, R. (1993) A hierarchical model for decomposition in terrrestrial ecosystems: application to soils of the humid tropics. Biotropica, 25, 130150.

Liski, J., Nissinen, A., Erhard, M. \& Taskinen, O. (2003) Climatic effects on litter decomposition from arctic tundra to tropical rainforest. Global Change Biology, 9, 575-584.

Lloyd, J. \& Taylor, J.A. (1994) On the temperature dependence of soil respiration. Functional Ecology, 8, 315-323.

Meentemeyer, V. (1978) Macroclimate and lignin control of litter decomposition rates. Ecology, 59, 465-472.

Meentemeyer, V. (1984) The geography of organic decomposition rates. Annals of the Association of American Geographers, 74, 551-560.

Melillo, J.M., Aber, J.D., Linkins, A.E., Ricca, A., Fry, B. \& Nadelhoffer, K.J. (1989) Carbon and nitrogen dynamics along the decay continuum: plant litter to soil organic matter. Plant and Soil, 115, 189-198. 
Moorhead, D.L. \& Sinsabaugh, R.L. (2006) A theoretical model of litter decay and microbial interaction. Ecological Monographs, 76, 151-174.

Moorhead, D.L., Currie, W.S., Rastetter, E.B., Parton, W.J. \& Harmon, M.E. (1999) Climate and litter quality controls on decomposition: an analysis of modeling approaches. Global Biogeochemical Cycles, 13, 575-589.

Olson, J.S. (1963) Energy storage and the balance of producers and decomposers in ecological systems. Ecology, 44, 322-331.

Ostertag, R. \& Hobbie, S.E. (1999) Early stages of root and leaf decomposition in Hawaiian forests: effects of nutrient availability. Oecologia, 121, 564 573.

Parton, W., Silver, W.L., Burke, I.C., Grassens, L., Harmon, M.E., Currie, W.S., King, J.Y., Adair, E.C., Brandt, L.A., Hart, S.C. \& Fasth, B. (2007) Global-scale similarities in nitrogen release patterns during long-term decomposition. Science, 315, 361-364.

Santiago, L.S. (2007) Extending the leaf economics spectrum to decomposition: evidence from a tropical forest. Ecology, 88, 1126-1131.

Sayer, E.J. (2006) Using experimental manipulation to assess the roles of leaf litter in the functioning of forest ecosystems. Biological Reviews, 81, 1-31.

Schlesinger, W.H. (1977) Carbon balance in terrestrial detritus. Annual Review of Ecology and Systematics, 8, 51-81.

Schuur, E.A.G. (2001) The effect of water on decomposition dynamics in mesic to wet Hawaiian montane forests. Ecosystems, 4, 259-273.

Schuur, E.A.G., Chadwick, O.A. \& Matson, P.A. (2001) Carbon cycling and soil carbon storage in mesic to wet Hawaiian montane forests. Ecology, 82, 3182-3196.

Seastedt, T.R. (1984) The role of microarthropods in decomposition and mineralization processes. Annual Review Entomology, 29, 25-46.

Silver, W.L. \& Miya, R.K. (2001) Global patterns in root decomposition: comparisons of climate and litter quality. Oecologia, 129, 407-419.

Singh, J.S. \& Gupta, S.R. (1977) Plant decomposition and soil respiration in terrestrial ecosystems. The Botanical Review, 4, 449-528.

Singh, K.P. (1969) Studies in decomposition of leaf litter of important trees of tropical deciduous forests at Varanasi. Tropical Ecology, 10, 292-311.

Swift, M.J., Heal, O.W. \& Anderson, J.M. (1979) Decomposition in Terrestrial Ecosystems. University of California Press, Berkeley.
Trofymow, J.A., Moore, T.R., Titus, B., Prescott, C., Morrison, I., Siltanen, M. et al. (2002) Rates of litter decomposition over 6 years in Canadian forests: influence of litter quality and climate. Canandian Journal of Forest Research, 32, 789-804.

Vitousek, P.M., Turner, D.R., Parton, W.J. \& Sanford, R.L. (1994) Litter decomposition on the Mauna Loa environmental matrix, Hawai'i: patterns, mechanisms, and models. Ecology, 75, 418-429.

Wall, D.H., Bradford, M.A., St. John, M.G., Trofymow, J.A., Behan-Pelletier, V., Bignell, D.E., et al. (2008) Global decomposition experiment shows soil animal impacts on decomposition are climate-dependent. Global Change Biology, 14, 1-17.

Wieder, R.K. \& Lang, G.E. (1982) A critique of the analytical methods used in examining decomposition data obtained from litter bags. Ecology, 63, $1636-1642$.

Received 24 October 2008; accepted 14 April 2009

Handling Editor: Hans Cornelissen

\section{Supporting Information}

Additional Supporting Information may be found in the online version of this article:

Fig. S1 Decay rates versus MAP plotted separately for each of eight treatment combinations.

Table S1 Study site locations, abbreviations and climate data

Appendix S1 Decay coefficients and goodness-of-fit metrics

Please note: Wiley-Blackwell are not responsible for the content or functionality of any supporting materials supplied by the authors. Any queries (other than missing material) should be directed to the corresponding author for the article. 